\title{
The phenomenon of root elongation and high respiration activity in the rolB-gene-enhanced FSL\#35 variant of Lotus corniculatus FOX-SR line
}

\author{
Tsubasa Yano ${ }^{1, \dagger}$, Akihiro Yamamoto ${ }^{2, \dagger}$, Hisato Kunitake ${ }^{2}$, Yuichi Saeki $^{2}$ and Ryo Akashi \\ ${ }^{1}$ Interdisciplinary Graduate School of Agriculture and Engineering, University of Miyazaki, 1-1 Gakuen Kibana- \\ dai-nishi, Miyazaki 889-2192, Japan \\ ${ }^{2}$ Faculty of Agriculture, University of Miyazaki, 1-1 Gakuen Kibanadai-nishi, Miyazaki 889-2192, Japan \\ $\dagger$ These authors contributed equally to this work. \\ Corresponding author: R. Akashi, E-mail: rakashi@cc.miyazaki-u.ac.jp, Phone: +81-985-58-7257, \\ Fax: +81-985-58-7257
}

Received on May 16, 2014; Accepted on August 24, 2014

\begin{abstract}
For systematic functional analysis of genes, we attempted the application of the FOX-hunting system to super growing-roots (SR) of legume species Lotus corniculatus which was previously reported by Himuro et al. (2011). In this study, we investigated the functional analysis of FSL\#35, which was expressed by the rolB gene derived from the Agrobacterium rhizogenes Ri plasmid. In monoculture roots grown in liquid media, the FSL\#35 showed specific phenotypes that increased root length, lateral root number and root surface area compared with SR. These enhanced phenotypes of FSL\#35 were caused by cell profile alteration, while increased total root length and increased lateral root number were caused by the expansion of cortex cells and increased pericycle cells, respectively. In addition, the FSL\#35 root showed high and specific respiration activity compared with SR. These results suggest that distinct cell profiles of FSL\#35 were induced by the alteration of respiration activity in root tissue. The enhanced root growth in the FSL\#35 root might be induced by alteration of ROS metabolisms. Investigating the details of the rolB gene function, for example by phytohormone analysis, will elucidate the novel benefits of the rolB gene for agriculture.
\end{abstract}

Keywords: FOX-SR line, Lotus corniculatus, respiration activity, rolB gene, root formation

\section{Introduction}

Plants assimilate nutrient elements and water through their roots (Somma et al. 1998). Roots have mechanisms that help them cope with soil conditions and adapt to obtain materials for increasing plant growth and seed yield (Kashiwagi et al. 2006). In legumes, the root is an area symbiotic with the rhizobium, and root nodules are formed as a symbiotic organ. The plant acquires fixed nitrogen from nodules in its roots. (Lodwig et al. 2003). Therefore, root responses are very important in plant growth and seed production.

Lotus corniculatus FOX-SR lines were created by using super growing root line (SR) (Himuro et al. 2010). The SR, allopolyploid Lotus corniculatus, has the capacity for a higher root growing speed than that of wild-type plants as well as continuous growth of monoculture roots in hormone-free liquid media (Akashi et al. 1998, 2003). Furthermore, SR has the capabilities of protoplast formation, redifferentiation to plants, and nodulation on the roots of redifferentiated plants (Tanaka et al. 2008, Jian et al. 2009). In a previous study, SR was used as the target for transformation method, full-length cDNA over-expressor gene (FOX) hunting system (Ichikawa et al. 2006). This method inserts CDNA of Arabidopsis thaliana to target plants with 35S promoter that is over expressing promoter. Using these resultant plant can rapidly and massively investigate gene functions compared with previous methods. One of the line of FOX-SR $\# 4$, created by inserting aquaporin gene AtPIP1;2, showed specific phenotypes that decreased in stem number, shoot dry weight, root mass and nodulation number, and increased in the ratio of shoot to root dry

Yano T, Yamamoto A, Kunitake H, Saeki Y, Akashi R 2014 The phenomenon of root elongation and high respiration activity in the rolB-gene-enhanced FSL\#35 variant of Lotus corniculatus FOX-SR line. Plant Root 8: 82-91. doi:10.3117/plantroot.8.82

Copyrights 2014, Plant Root (JSRR), www.plantroot.org 
weight (Himuro et al. 2010). These phenotypes corresponded to those of other plants investigated for aquaporin expression (Kaldenhoff et al. 1998, Aharon et al. 2003). Furthermore, some FOX-SR lines, FSL\#6, \#55, \#78 showed root elongation than SR line (Himuro et al. 2011). Thus, FOX-SR lines are useful for investigating the phenotypes caused by exogenous gene expression.

In the present study, we investigated root responses of FSL\#35 that also showed root elongation compared with SR (Himuro et al. 2011). FSL\#35 showed of rolB sequence and its expression. In addition, we carried out analysis of the roots based on root elongation patterns, lateral root formation and cell size.

\section{Materials and Methods}

\section{Plant materials and growth conditions}

Parental SR and FSL\#35 were used in the present study; the FSL\#35 was created in our previous study (Himuro et al. 2011). Material roots were isolated from the root tissue of regenerated plants grown and sustained in plant boxes containing hormone-free 1/2-MS medium (Murashige and Skoog 1962) with $0.7 \%$ agar solid medium in growth chamber under a light/dark cycle of $17 / 7 \mathrm{~h}, 140 \mu \mathrm{mol} \mathrm{m}^{-2} \mathrm{~s}^{-1}$, at $27^{\circ} \mathrm{C}$. To prepare monoculture root tissue, 2 -cm root tissues containing root tips from regenerated plant roots were cultured in $20 \mathrm{~mL}$ MS liquid medium in the dark at $27^{\circ} \mathrm{C}$ with gyratory culturing at $110 \mathrm{rpm}$. Monocultured roots were subcultured in fresh MS liquid medium every 2 weeks.

\section{Expression analysis}

Reverse transcriptase-polymerase chain reaction (RT-PCR) was performed to confirm the expression of the rolB gene in FSL\#35. Total RNA was extracted using an RNeasy Plant Mini Kit (Qiagen, Hilden, Germany) from FSL\#35 roots as a template to create cDNA following the manufacturer's instructions. Extracted total RNA was reverse-transcribed using PrimeScript RT Master Mix (Perfect Real Time; Takara, Shiga, Japan). The created cDNA and primers for the rolB gene, L35-RT3-Fw (5'-GGTCACTTTTAACTCCAGCAAG-3')/L35-RT 3-Rv (5'-AGAAAGTGCTGAAGGAACAATC-3') and for ACTIN 1 as a reference gene, Lc-actin-Fw (5'-ACAATGAGTTGCGTGTTGCT-3')/Lc-actinRv (5'-ACTCACACCATCACCGGAAT-3'), were used to perform RT-PCR. These primers for the detection of the rolB gene expression were designed by sequence analysis of FSL\#35 genomic DNA, and the sequences of reference gene primers were selected based on the results of our previous study (Himuro et al. 2011). The PCR conditions for the investigation of the rolB gene and ACTIN 1 gene expression were as follows: 5 min at $94^{\circ} \mathrm{C}$ for denaturation, followed by 30 cycles of $30 \mathrm{sec}$ at $94^{\circ} \mathrm{C}$ for denaturation, $30 \mathrm{sec}$ at $55^{\circ} \mathrm{C}$ for annealing, and $1 \mathrm{~min}$ at $72^{\circ} \mathrm{C}$ for elongation. PCR products were then separated by 3.0\% agarose gel electrophoresis in TBE buffer, and band sizes were checked by ethidium bromide staining using FUJI LAS-4000 (Fujifilm, Tokyo, Japan).

FSL\#35 root analysis under monoculture of root tissues

We investigated individual root elongation under monoculture conditions. SR and FSL\#35 roots were cut into 2-cm pieces, which were then incubated in 50-mL flasks containing hormone-free MS medium. We prepared 4 flasks for each line. Root length, average root diameter and surface area were analyzed every week by image analysis using WinRHIZO Arabidopsis software (Regent Instruments Inc., Quebec, Canada). This analysis was performed for 5 independent experiments.

\section{Measurement of respiration activity}

Triphenyltetrazolium chloride (TTC) reduction activity was used to measure respiration activity (Block and Brouwer 2002). Root tip tissues $2 \mathrm{~cm}$ long were cultured in hormone-free MS liquid medium for 2 weeks, after which lateral roots were removed from cultured roots, cut into $5-\mathrm{cm}$ pieces, and incubated overnight in TTC solution (0.5\% TTC, $0.05 \%$ sodium phosphate buffer) at $30^{\circ} \mathrm{C}$ in the dark. After incubation, photos of whole root tissues were taken to compare formazan concentration patterns between SR and FSL\#35. Additionally, the roots were rinsed with distilled water three times, and cut every $1 \mathrm{~cm}$ to measure formazan contents. Each root section was placed in a $1.5-\mathrm{mL}$ tube with $1 \mathrm{~mL} 95 \%$ ethanol and incubated for $5 \mathrm{~min}$ at $85^{\circ} \mathrm{C}$ to extract formazan. As a control, root sections boiled for 10 min were subjected to the same treatment. The absorbance at $470 \mathrm{~nm}$ of formazan dissolved in 95\% ethanol was measured by spectrophotometer (Shimadzu, Kyoto, Japan).

\section{Microscopy analysis}

To measure cell size in root tissues by microscope, we embedded root tissues in resin, and made preparations from the embedded tissues. One-cm root fragments containing root tips were cut from SR and FSL\#35 root tissue cultured for 2 weeks. These root fragments were fixed by deaeration in FAA solution (formalin: acetic acid: ethyl alcohol: distilled water = 
1:1:9:9). After fixation, the root fragments were dehydrated by ethanol series (60, 80, 90, 99.5, 100\%), and dehydrated tissues were embedded in Technovit 7100 resin (Heraeus Kulzer, Wehrheim, Germany). After the embedded root tissues were trimmed, thin sections were cut using a microtome for microscopic observation. Thin sections were stained by $0.05 \%$ toluidine blue in $0.1 \mathrm{M}$ phosphate buffer ( $\mathrm{pH}$ 6.8) for $1 \mathrm{~min}$, then rinsed with distilled water. The stained sections were observed and photographed using an ECLIPSE E600 microscope with a DXM1200F digital camera (Nikon, Tokyo, Japan). The Image J software (National Institutes of Health, Bethesda, MD, USA) was used to measure cell size.

\section{Statistical analysis}

The Student's $t$-test was used to compare SR and FSL\#35. A difference of $P<0.05$ was considered significant.

\section{Results}

\section{Expression of the rolB gene in FSL\#35}

Sequence analysis identified the $\mathrm{rolB}$ gene construct in the FSL\#35 gene, and expression analysis of the rolB gene was carried out. Total RNAs of SR and FSL\#35 plants were extracted from the roots of regenerated plants. After reverse transcription of total RNA, we performed RT-PCR to investigate the expression of the rolB gene in FSL\#35 plants. Using electrophoresis, the expression of the $\mathrm{rolB}$ gene was detected in FSL\#35 cDNA (Fig. 1), however, no such expression was detected in SR cDNA. Furthermore, the $r o l B$ gene expression was detected in the roots of FSL\#35 regenerated plants. These results indicate that the expression of the rolB gene in FSL\#35 has an
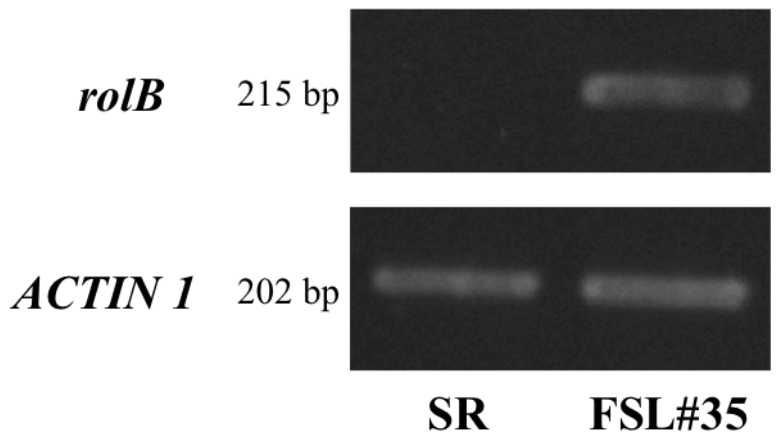

Fig. 1. Expression analysis of the rolB gene by RT-PCR in SR and FSL\#35. The upper panel shows the rolB gene expression of SR and FSL\#35; the lower panel the expression of the ACTIN 1 gene used as an internal standard. effect on some specific phenotypes determined in the present study.

\section{Root analysis of monocultured root tissues}

To investigate the effect of the rolB gene on root phenotypes, we analyzed root length, average root diameter and surface area. An increase in total root length and root surface area were detected in FSL\#35 compared with SR (Figs. 2A and 2C). The FSL\#35 roots showed a total root length doubled compared with that of SR roots. In addition, the lateral root number in FSL\#35 tripled and doubled than those in SR at 21 and 28 days of culture, respectively (Fig. 2B). On the other hand, the average root diameter of FSL\#35 showed no significant difference compared with SR (Fig. 2D). FSL\#35 roots showed greater enhancement of root elongation than SR roots.

\section{Measurement of respiration activity}

Figures $3 \mathrm{~A}$ and $3 \mathrm{~B}$ shows images of whole roots of SR and FSL\#35 demonstrating a different pattern of formazan concentration between the two lines. We therefore analyzed formazan contents in these roots. Formazan content was increased in all analyzed sections of FSL\#35 compared with SR (Fig. 3C). Furthermore, the location of the greatest respiration activity was different between FSL\#35 and SR, with high respiration in the second section from the root tip in FSL\#35 (Fig. 3C). The highest respiration point of FSL\#35 was 55\% higher than that of SR.

\section{Measurement of FSL\#35 cell size}

FSL\#35 roots showed enhanced root growth phenotypes compared with SR roots. We analyzed cell shape profiles in roots cultured for 2 weeks. The cortex cells of FSL\#35 roots showed cell expansion in the vertical direction (Figs. 4A, 4B and Table 1). On the other hand, width was essentially the same in FSL\#35 and SR. (Table 1). Pericycle cell sizes in FSL\#35 roots were reduced in vertical direction compared to those in SR roots (Figs. 4C, 4D and Table 2). In addition, those cells in developed roots had expanded in the horizontal direction (Table 2). These results clearly show different profiles of the cortex and pericycle cells in FSL\#35 roots.

\section{Discussion}

The rolB gene is the expressing gene in FSL\#35 Line

We have analyzed of FSL\#35 in FOX-SR lines, which was expressed by the rolB gene derived from the Agrobacterium rhizogenes Ri plasmid (Fig. 1). The 
A

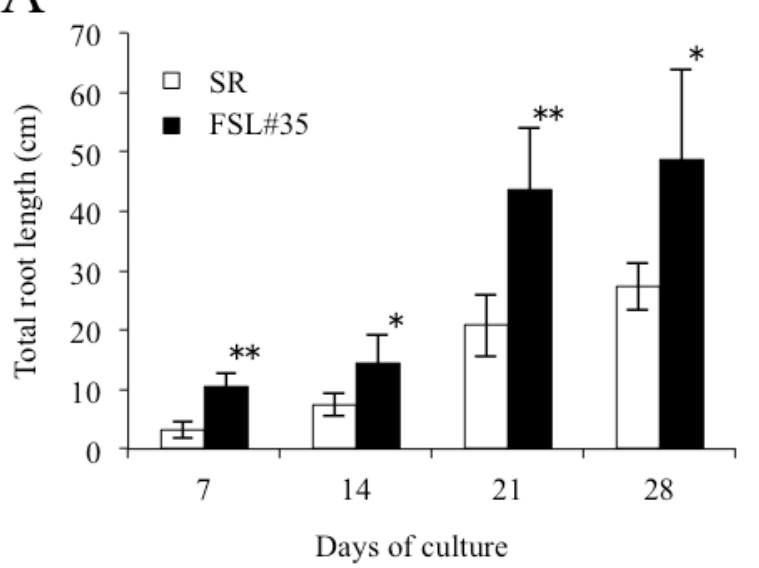

B

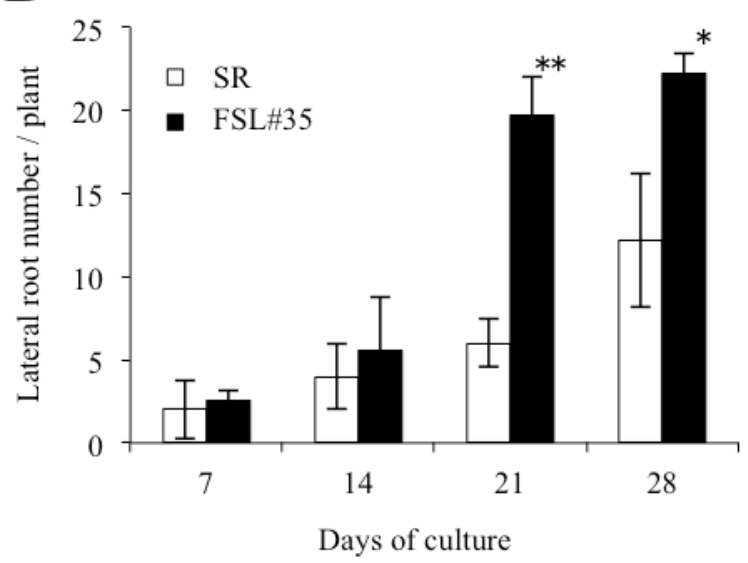

$\mathrm{C}$

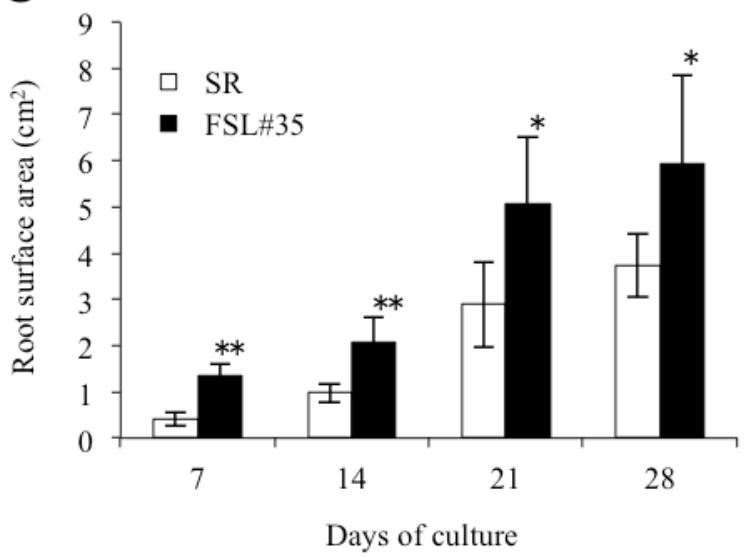

$\mathrm{D}$

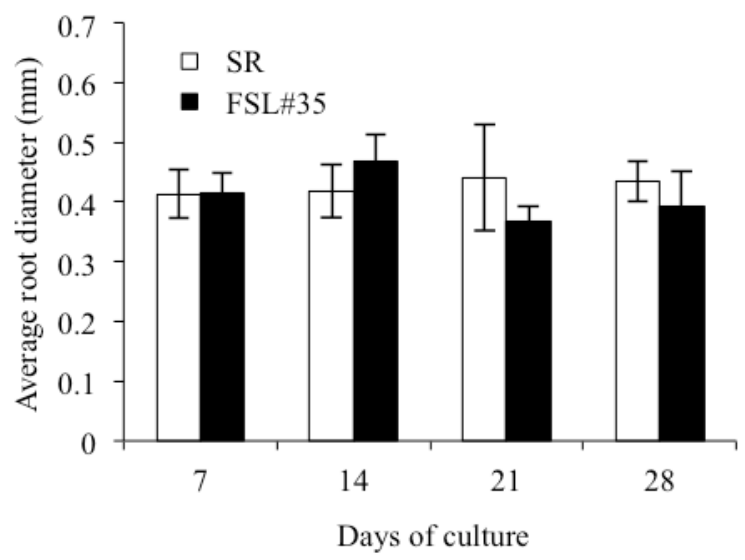

Fig. 2. Root properties under independent culture in MS liquid medium. (A) Total root length, (B) lateral root number, (C) root surface area, and (D) average root diameter of FSL\#35 and SR after culturing 2-cm root tissues. Results are expressed as the means \pm SD from 3 independent experiments. The data were analyzed by Student's $t$-test. Statistical significance was defined as $* * P<0.01$ and $* P<0.05$.

original FOX system constructed an Agrobacterium expression library that contained approximately 10,000 normalized Arabidopsis full-length cDNAs (Ichikawa et al. 2006). The rolB gene was one of the internal standard genes used as an indication to measure transformation efficiency. Previous reports have elucidated the role of the $\mathrm{rolB}$ gene in lateral and adventitious root formations (Cardarelli et al. 1987, Capone et al. 1989, Moriuchi et al. 2004). Although the effect of the rolB gene expression was not shown in the FOX hunting system study for A. thaliana (Ichikawa et al. 2006), our results showed that FSL\#35 lines had exhibited specific phenotypes corresponding to those expressing the $\mathrm{rolB}$ gene. Normally, gene expression studies require several lines to analyze. However, only FSR\#35 showed lateral root phenotypes among all the FOX-SR lines. This study offers another possible approach for the introduction and further investigation of the rolB gene functions in legumes.
The rolB gene, one of the TL-DNA genes in $\mathrm{Ag}$ robacterium rhizogenes $\mathrm{Ri}$-plasmid, has been reported to be a causal gene for the formation of hairy roots on stem infection sites in plants (Cardarelli et al. 1987, Nilsson and Olsson 1997, Aoki and Syōno 1999). Previous studies using transformed tobacco showed that the rolB gene enhanced root formation when acting with rolA or rolC (Spena et al. 1987). However, the function of the rolB gene is not only limited to root formation but also acts in the de novo formation of floral and shoot meristems (Altamura et al. 1994, Koltunow et al. 2001), the induction of parthenocarpy (Carmi et al. 2003), and delays in pistil and anther development (Cecchetti et al. 2004). In tobacco plants with a rolB gene homolog, it has been reported that the balance between the proliferation of procambial cells and xylem differentiation is modified during stamen development (Cecchetti et al. 2007). Furthermore, the rolB gene expression in plant cells suppresses programmed cell death (Bulgakov et al. 2012, 

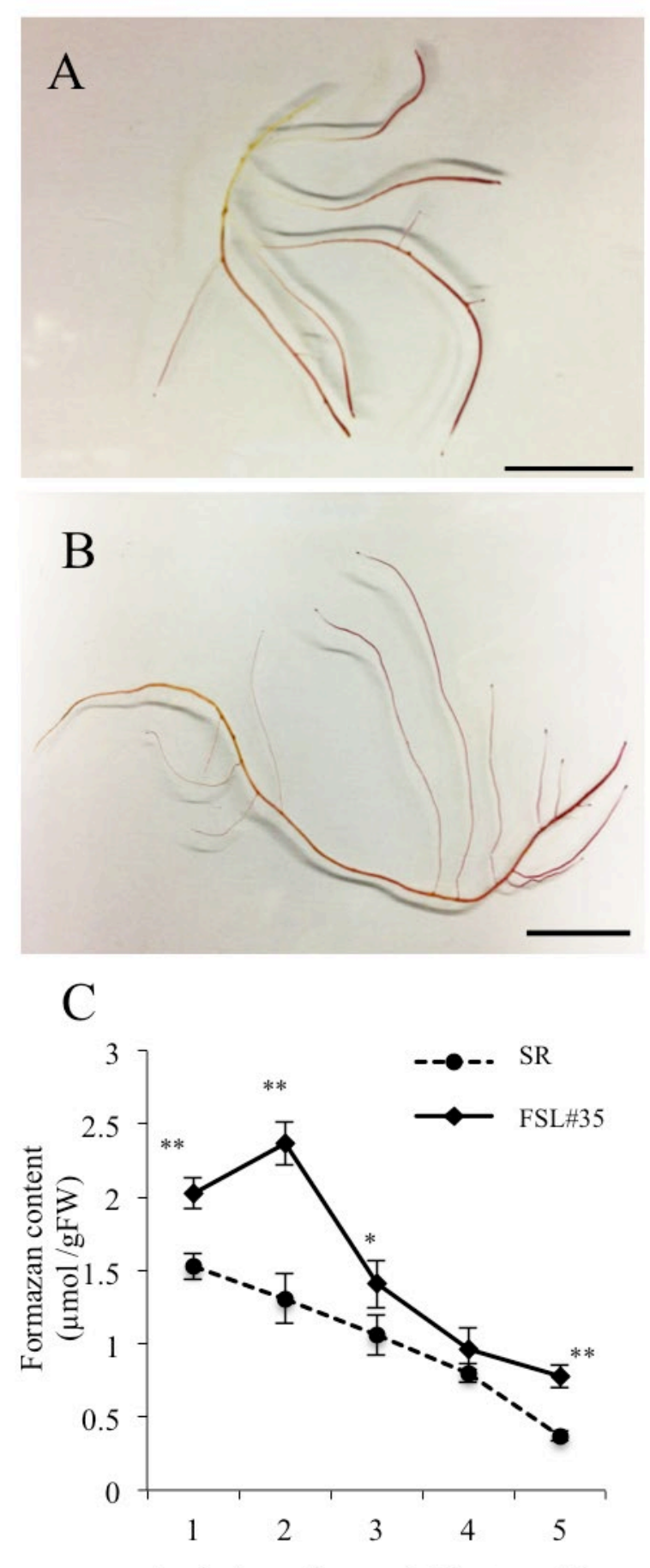

Analysis sections point from root tip $(\mathrm{cm})$

Fig. 3. Responses of TTC reducing activity in in SR and FSL\#35. (A) is SR root appearance and (B) is FSL\#35 root after incubation in TTC solution. Black bar indicates $2 \mathrm{~cm}$. (C) Relative contents of formazan in FSL\#35 and SR at $470 \mathrm{~nm}$ absorbance. Results are expressed as means \pm SD from 3 independent experiments. The data were analyzed by Student's $t$-test. Statistical significance was defined as ${ }^{* *} P<0.01$ and $*_{P}<0.05$.
Gorpenchenko et al. 2012), and this suppression of cell death is caused by the down-regulation of reactive oxygen species (ROS) production relating to oxidative stress (Bulgakov et al. 2012). Based on these reports, the rolB gene expression may have useful applications for crops due to its effects on shoot phenotypes and tolerance of oxidative stress, though the effects of the rolB gene expression on root phenotype are not well known. It is suggested that the $\mathrm{rolB}$ gene might affect for particular species such as legume. Our results suggest that the expression of the rolB gene might affect particular species such as legume.

Enhancement of root growth in FSL\#35 by the rolB gene expression

The rolB, rolA and rolC genes are responsible for hairy root formation. Hairy root formation on infection sites of Agrobacterium rhizogenes was caused by concerted expression of these genes of $A$. rhizogenes in plant cells (Spena et al. 1987). However, these genes also have independent functions in plant cells. In a single-cell assay, rolC was found to suppress ROS level, and is known to regulate ROS production in Rubia cordifolia cells (Bulgakov et al. 2008). With respect to the rolB gene expression in cells, regulation of ROS metabolism (Bulgakov et al. 2012), suppression of programmed cell death (Gorpenchenko et al. 2012) and enhancement of cell proliferation by auxin sensitivity (Spanò et al. 1988, Maurel et al. 1994) have been reported. Furthermore, although the rolB gene expression is known to affect plant phenotypes (Cecchetti et al. 2007) and cell metabolism (Bulgakov et al. 2012, Gorpenchenko et al. 2012), it has been reported that it did not affect any phenotypes of $A$. thaliana (Ichikawa et al. 2006). We investigated further effects of rolB expression in legume plants, especially in root tissue, finding effects of the rolB gene expression in independent legume root tissue.

In the present study, FSL\#35 roots showed growth enhancement and increased root length, lateral root number and root surface area compared with SR roots (Figs. 2A, 2B and 2C). However, average root diameters were similar in SR and FSL\#35 roots (Fig. 2D). These results suggest that increased root length and lateral root number may have caused expansion of the root surface area. These distinct phenotypes were considered to be the results of cell profile alteration. Specifically, the increased total root length and lateral root number might be caused by expansion in the vertical direction of cortex cells and increased pericycle cells, respectively (Tables 1 and 2). Increase of lateral root number in FSL\#35 is consisted with the case that hairy root clones expressed higher level of the rolB gene exhibited greater branch root (Wang et 

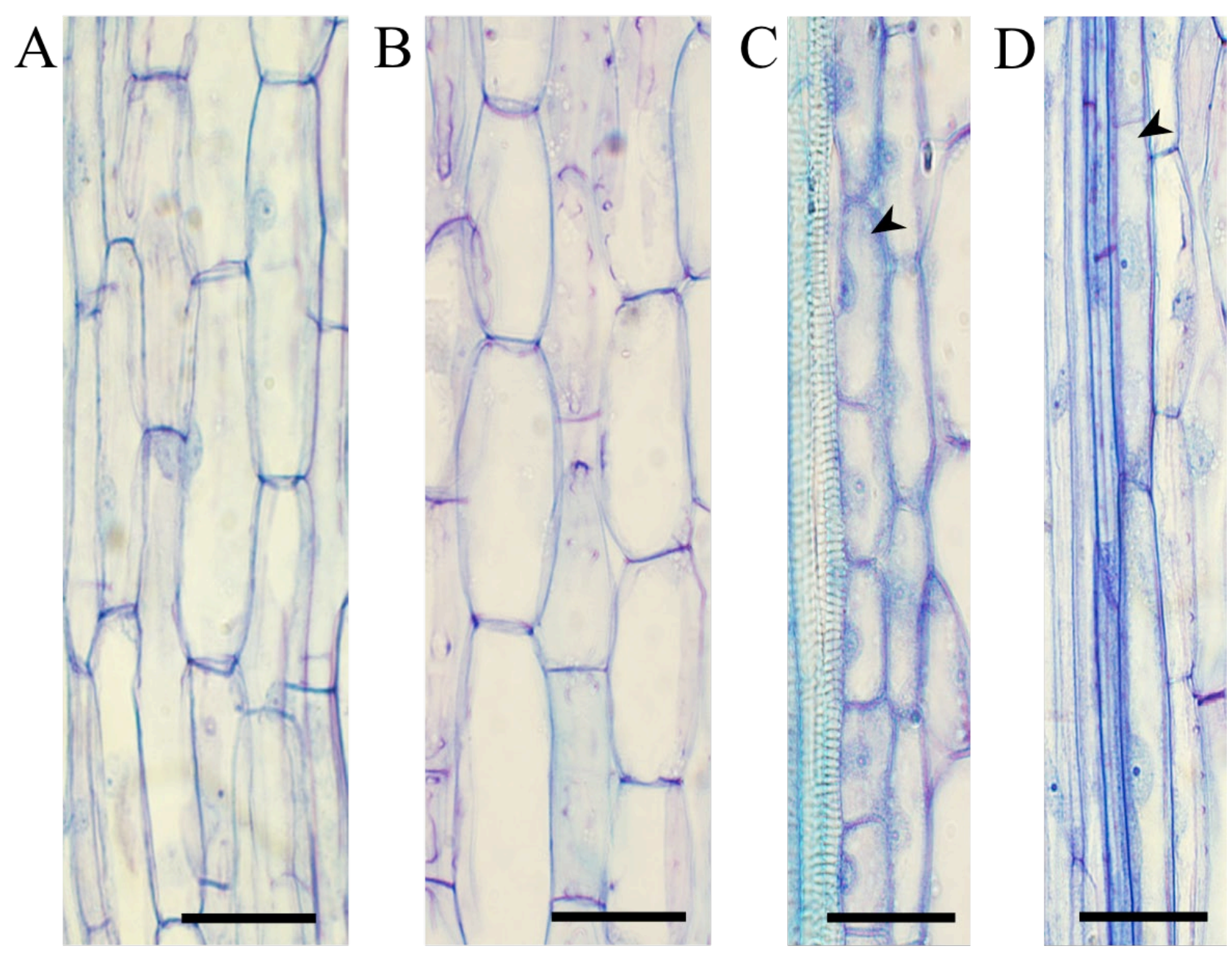

Fig. 4. Root cross sections. (A) Cortex cells in a FSL\#35 root; (B) cortex cells in an SR root; (C) pericycle cells in a FSL\#35 root, and (D) pericycle cells in an SR root. Black bar indicates $50 \mu \mathrm{m}$. Black arrowheads indicate a pericycle cell.

al. 2014). It is reported that the rolB gene expression modifies the balance between the proliferation of procambial cells and xylem differentiation during stamen development (Cecchetti et al. 2007). In addition, the promoters of $\mathrm{rolB}$ gene and $\mathrm{rolC}$ gene were found to be activated in pericycle cells that have the capacity to redifferentiate to lateral roots (Nilsson et al. 1997). Moreover, the rolB gene is responsible for the induction of adventitious root formations (Cardelli et al. 1987), and was shown to induce lateral adventitious root formations under tissue culture conditions (Capone et al. 1989). Furthermore, the function of the rolB gene in the induction of adventitious root formation had been elucidated. The $r o l B$ gene requires an interaction with $14-3-3$ protein or localization in the nucleus for the induction of adventitious roots (Moriuchi et al. 2004). We believe that the increase in lateral root number in FSL\#35 in the present study was caused by the $\mathrm{rol} B$ gene expression that activates redifferentiation and induces the formation of vascular bundle tissues such as xylem. Additionally, although some plant species such as apple showed advantageous characters (especially enhanced rooting) by introduction with the $\mathrm{rolB}$ gene (Zhu et al. 2001, Radchuk and Korkhovoy 2005), most of the rolB-transgenic plants displayed severe and disadvantageous phenotypes such as abnormal differentiation (Spena et al. 1987), necrosis and wrinkled leaf (Röder et al. 1994) that caused by high the rolB gene expression. Root elongation in FSL\#35 regenerated plant significantly differed from SR (Himuro et al. 2011), however, shoot characteristics were similar for both FSL\#35 and SR lines (Data not shown). These knowledge and the results may indicate that favorable root responses, including normal shoot reactions of FSL\#35 were caused by mild expression of the rolB gene.

\section{Alteration of respiration activity and cell profiles}

FSL\#35 roots showed distinct phenotypes, such as increased growth level and lateral root number, that 
Table 1. Cell size of cortex cells on lateral roots and taproots of monocultured roots.

\begin{tabular}{|c|c|c|c|c|}
\hline & \multicolumn{2}{|c|}{ Lateral root $(\mu \mathrm{m})$} & \multicolumn{2}{|c|}{ Taproot $(\mu \mathrm{m})$} \\
\hline & Tip & Base & Tip & Base \\
\hline \multicolumn{5}{|l|}{ Vertical direction } \\
\hline $\mathrm{SR}$ & $57.7 \pm 10.3$ & $80.4 \pm 12.8$ & $66.1 \pm 17.3$ & $80.6 \pm 12.4$ \\
\hline FSL\#35 & $85.9 \pm 15.1^{* *}$ & $110.2 \pm 19.6^{*}$ & $99.4 \pm 17.2^{* *}$ & $107.2 \pm 11.9 * *$ \\
\hline \multicolumn{5}{|c|}{ Horizontal direction } \\
\hline SR & $17.5 \pm 12.9$ & $18.6 \pm 12.2$ & $29.0 \pm 13.4$ & $29.4 \pm 13.5$ \\
\hline FSL\#35 & $20.7 \pm 12.7$ & $20.6 \pm 11.5$ & $35.7 \pm 12.6^{* *}$ & $29.1 \pm 15.5$ \\
\hline
\end{tabular}

Results are expressed as means \pm SD from 5 replications. The data were analyzed by Student's $t$-test. Statistical significance was defined as $* * P<0.01$ and $* P<0.05$.

Table 2. Cell size of pericycle cells on the lateral roots and taproots of monocultured roots.

\begin{tabular}{|c|c|c|c|c|}
\hline & \multicolumn{2}{|c|}{ Lateral root $(\mu \mathrm{m})$} & \multicolumn{2}{|c|}{ Taproot $(\mu \mathrm{m})$} \\
\hline & Tip & Base & Tip & Base \\
\hline \multicolumn{5}{|l|}{ Vertical direction } \\
\hline SR & $46.7 \pm 11.9$ & $66.8 \pm 18.1$ & $73.0 \pm 15.3$ & $87.2 \pm 17.0$ \\
\hline FSL\#35 & $34.9 \pm 14.8^{* *}$ & $43.3 \pm 18.9 * *$ & $48.4 \pm 17.0^{* *}$ & $53.0 \pm 18.9 * *$ \\
\hline \multicolumn{5}{|c|}{ Horizontal direction } \\
\hline SR & $7.8 \pm 10.4$ & $7.1 \pm 10.9$ & $9.9 \pm 11.7$ & $9.7 \pm 11.4$ \\
\hline FSL\#35 & $8.3 \pm 10.5$ & $8.8 \pm 10.4^{* *}$ & $15.1 \pm 11.7^{* *}$ & $14.7 \pm 11.0^{* *}$ \\
\hline
\end{tabular}

Results are expressed as means \pm SD from 5 replications. The data were analyzed by Student's $t$-test. Statistical significance was defined as $* * P<0.01$ and $* P<0.05$.

might be caused by changing cell profiles. To investigate these changes, respiration activity was measured by TTC reduction assay. TTC is converted to formazan by dehydrogenase catalysis, especially dehydrogenase in the mitochondrial electron transport system (Block and Brouwer 2002). TTC reduction assay indicates the level of respiration activity in plant tissues, because the efficiency of color and stable formazan formation by TTC reduction depends on cytochrome activity (Block and Brouwer 2002). TTC reduction assay has been used for several different types of evaluation: seed germination rate (Bennett and Loomis, 1949), cold injury estimation (English ivy; Steponkus and Lanphear 1967, rice seedlings; Lee et al. 1997), and salt stress estimation (Atia et al. 2011). In the present study, after 2 weeks of culturing, FSL\#35 roots showed a different pattern of formazan accumulation from that of SR roots. We detected formazan accumulation in the entire cultured FSL\#35 root (Fig. 3B), while SR roots showed formazan accumulation in only a few $\mathrm{cm}$ from the root tip (Fig. $3 \mathrm{~A})$. To investigate these reaction patterns in greater detail, formazan contents were analyzed for 5 sections, every $1 \mathrm{~cm}$ from the root tip. The FSL\#35 roots showed higher respiration activity than SR roots (Fig. 3C), and their highest respiration activity area (second section from the root tip) was different from that of SR roots (root tip). This suggests that high respiration areas such as the root meristematic zone in FSL\#35 roots were expanded. In general, plant cells increase respiration and ROS production under stress conditions (Tiwari et al. 2002). The rolB gene is involved in suppression of oxidative stress, especially through the enhancement of antioxidant enzyme genes that catalyze ROS (Bulgakov et al. 2012, Gorpenchenko et al. 2012), and the suppression of programmed cell death (Gorpenchenko et al. 2012). In view of the fact that 14-3-3 proteins were shown to be involved in regulation of ROS (Elmayan et al. 2007), it is tempting to speculate that the RolB-14-3-3 complex might be involved in ROS metabolism, whereby causing subsequent morphological responses. The present study did not examine stress conditions, under which an increase in respiration might not induce a stress response but possibly a change in ROS metabolism.

\section{Conclusion}

In the present study, we were able to demonstrate new plant root responses due to the rolB gene expression. FSL\#35 roots showed increased growth and lateral root number by alteration of cell profiles. The rolB gene has been successfully used for the improvement of crop quality and resistance against biotic and 
abiotic stress. Recently, Agrobacterium-mediated transformation with the rolB gene was reported to have enhanced fruit quality and foliar resistance against fungal pathogens in tomato (Arshad et al. 2014). The rolB gene expression also caused high root extension in this study, which might lead to productive crops. Evidence from several studies support the relationship between the rolB gene and auxin. In tobacco protoplasts in which the $\operatorname{rol} B$ gene has been inserted, a transmembrane potential is induced by auxin at a concentration 10,000 times lower than that required to induce the same effect in untransformed protoplasts (Maurel et al. 1994). The rolB gene is not affected by the concentration of intercellular auxin, but auxin sensitivity (Delbarre et al. 1994). Additionally, auxin is an important factor in lateral root formation (Laskowski et al. 1995, Casimiro et al. 2001), and cell expansion (Jones et al. 1998). Furthermore, auxin has a relationship with respiration activity and ROS production; it induces ROS signal (Joo et al. 2001), and affects respiration activity through water uptake during gravitropic reactions (Katou and Furumoto 1986). In the present study, regulation of the ROS metabolic enzyme gene and auxin sensitivity by the rolB gene expression might enhance respiration activity. It is predicted that the observed increase in lateral root formation in FSL\#35 was caused by an alteration of cell character, which might be induced by the increased auxin sensitivity derived from the rolB gene expression. Further investigation is required on phyto-hormone profiles including that of auxin in FSL\#35. Additionally, measurement of the FSL\#35 root under stress conditions that relates to ROS production should also be addressed. It is important to unravel the functions of the rolB gene as a gene resource for legume plants.

\section{References}

Aharon R, Shahak Y, Wininger S, Bendov R, Kapulnik Y, Galilia G 2003 Overexpression of a plasma membrane aquaporin in transgenic tobacco improves plant vigor under favorable growth conditions but not under drought or salt stress. Plant Cell 15: 439-447.

Akashi R, Hoffmann-Tsay S-S, Hoffmann F 1998 Selection of a super-growing legume root culture that permits controlled switching between root cloning and direct embryogenesis. Theor. Appl. Genet. 96: 758-764.

Akashi R, Kawano T, Hashiguchi M, Kutsuna Y, Hoffmann-Tsay S-S, Hoffmann F 2003 Super roots in Lotus corniculatus: a unique tissue culture and regeneration system in a legume species. Plant Soil 255: 27-33.

Altamura MM, Capitani F, Gazza L, Capone I, Costantino P 1994 The plant oncogene rolB stimulates the formation of flowers and root meristemoids in tobacco thin cell layers. New Phytol. 126: 283-293.

Aoki S, Syōno K 1999 Horizontal gene transfer and mutation: Ngrol genes in the genome of Nicotiana glauca. Proc.
Natl. Acad. Sci. U. S. A. 96: 13229-13234.

Arshad W, Haq IU, Waheed MT, Mysore KS, Mirza B 2014 Agrobacterium-mediated transformation of tomato with rolB gene results in enhancement of fruit quality and foliar resistance against fungal pathogens. PLoS One. 9: e96979.

Atia A, Abdelly C, Smaoui A 2011 ROS accumulation and TTC reduction in growing embryo of Crithmum maritimum L. isolated from water or salt imbibed seeds. Not. Sci. Biol. 3: 98-103.

Bennett N, Loomis WE 1949 Tetrazolium chloride as a test reagent for freezing injury of seed corn. Plant Physiol. 24: 162-174.

Block MD, Brouwer DD 2002 A simple and robust in vitro assay to quantify the vigour of oilseed rape lines and hybrids. Plant Physiol. Biochem. 40: 845-852.

Bulgakov VP, Aminin DL, Shkryl YN, Gorpenchenko TY, Veremeichik GN, Dmitrenok PS, Zhuravlev YN 2008 Suppression of reactive oxygen species and enhanced stress tolerance in Rubia cordifolia cells expressing the rolC oncogene. Mol. Plant-Microbe Interact. 21: 1561-1570.

Bulgakov VP, Gorpenchenko TY, Veremeichik GN, Shkryl YN, Tchernoded GK, Bulgakov DV, Aminin DL, Zhuravlev YN 2012 The rolB gene suppresses reactive oxygen species in transformed plant cells through the sustained activation of antioxidant defense. Plant Physiol. 158: 1371-1381.

Cardarelli M, Mariotti D, Pomponi M, Spanò L, Capone I, Costantino P 1987 Agrobacterium rhizogenes T-DNA genes capable of inducing hairy root phenotype. Mol. Gen. Genet. 209: 475-480.

Carmi N, Salts Y, Dedicova B, Shabtai S, Barg R 2003 Induction of parthenocarpy in tomato via specific expression of the rolB gene in the ovary. Planta 217: 726-735.

Capone I, SpanoÁ L, Cardarelli M, Bellincampi D, Petit A, Costantino P 1989 Induction and growth properties of carrot roots with different complement of Agrobacterium rhizogenes T-DNA. Plant Mol. Biol. 13: 43-52.

Casimiro I, Marchant A, Bhalerao RP, Beeckman T, Dhooge S, Swarup R, Graham N, Inzé D, Sandberg G, Casero PJ, Bennettb M 2001 Auxin transport promotes Arabidopsis lateral root initiation. Plant Cell 13: 843-852.

Cecchetti V, Altamura MM, Serino G, Pomponi M, Falasca G, Costantino P, Cardarelli M 2007 ROX1, a gene induced by rolB, is involved in procambial cell proliferation and xylem differentiation in tobacco stamen. Plant J. 49: 27-37.

Cecchetti V, Pomponi M, Altamura MM, Pezzotti M, Marsilio S, D’Angeli S, Tornielli GB, Costantino P, Cardarelli M 2004 Expression of rolB in tobacco flowers affects the coordinated processes of anther dehiscence and style elongation. Plant J. 38: 512-525.

Delbarre A, Muller P, Imhoff V, Barbier-Brygoo H, Maurel C, Leblanc N, Perrot-Rechenmann C, Guern J 1994 The rolB gene of Agrobacterium rhizogenes does not increase the auxin sensitivity of tobacco protoplasts by modifying the intracellular auxin concentration. Plant Physiol. 105: 563-569.

Elmayan T, Fromentin J, Riondet C, Alcaraz G, Blein JP, Simon-Plas F 2007 Regulation of reactive oxygen species production by a 14-3-3 protein in elicited tobacco cells. Plant Cell Environ. 30: 722-732.

Gorpenchenko TY, Aminin DL, Vereshchagina YV, Shkryl YN, Veremeichik GN, Galina K, Bulgakov VP 2012 Can plant oncogenes inhibit programmed cell death? The rolB 
oncogene reduces apoptosis-like symptoms in transformed plant cells. Plant Signaling Behav. 7: 1058-1061.

Himuro Y, Tanaka H, Hashiguchi M, Ichikawa T, Nakazawa M, Seki M, Fujita M, Shinozaki K, Matsui M, Akashi R, Hoffmann F 2011 FOX-superroots of Lotus corniculatus, overexpressing Arabidopsis full-length cDNA, show stable variations in morphological traits. J. Plant Physiol. 168: 181-187.

Himuro Y, Tanaka H, Hashiguchi M, Yamashige R, Simajiri Y, Akashi R 2010 Characteristics of FSL-PIP-\#4 as overexpressed by Arabidopsis thaliana plasma membrane aquaporin gene, AtPIP1;2. Root Res. 19: 143-149. (in Japanese with English abstract)

Ichikawa T, Nakazawa M, Kawashima M, Iizumi H, Kuroda H, Kondou Y, Tsuhara Y, Suzuki K, Ishikawa A, Seki M, Fujita M, Motohashi R, Nagata N, Takagi T, Shinozaki K, Matsui M 2006 The FOX hunting system: an alternative gain-of-function gene hunting technique. Plant J. 45: 974-985.

Jian B, Hou W, Wu C, Liu B, Liu W, Song S, Bi Y, Han T 2009 Agrobacterium rhizogenes-mediated transformation of superroot-derived Lotus corniculatus plants: a valuable tool for functional genomics. BMC Plant Biol. 9: 78-91.

Jones AM, Im KH, Savka MA, Wu MJ, DeWitt NG, Shillito R, Binns AN 1998 Auxin-dependent cell expansion mediated by overexpressed auxin-binding protein 1 . Science 282 : 1114-1117.

Joo JH, Bae YS, Lee JS 2001 Role of auxin-induced reactive oxygen species in root gravitropism. Plant Physiol. 126: 1055-1060.

Kaldenhoff R, Grote1 K, Zhu J, Zimmermann U 1998 Significance of plasmalemma aquaporins for water-transport in Arabidopsis thaliana. Plant J. 14: 121-128.

Kashiwagi J, Krishnamurthy L, Crouch JH, Serraj R 2006 Variability of root length density and its contributions to seed yield in chickpea (Cicer arietinum L.) under terminal drought stress. Field Crops Res. 95: 171-181.

Katou K, Furumoto M 1986 A mechanism of respiration-dependent water uptake enhanced by auxin. Protoplasma 33: 174-185.

Koltunow AM, Johnson SD, Lynch M, Yoshihara T, Costantino P 2001 Expression of rolB in apomictic Hieracium piloselloides Vill. causes ectopic meristems in planta and changes in ovule formation, where apomixis initiates at higher frequency. Planta 214: 196-205.

Laskowski MJ, Williams ME, Nusbaum HC, Sussex IM 1995 Formation of lateral root meristems is a two-stage process. Development 121: 3303-3310.

Lee TM, Lur HS, Chu C 1997 Role of abscisic acid in chilling tolerance of rice (Oryza sativa L.) seedlings.: II. Modulation of free polyamine levels. Plant Sci. 126: 1-10.

Lodwig EM, Hosie AHF, Bourde`s A, Findlay K, Allaway D, Karunakaran R, Downie JA, Poole PS 2003 Amino-acid cycling drives nitrogen fixation in the legume-Rhizobium symbiosis. Nature 422: 722-726.

Maurel C, Leblanc N, Barbier-Brigoo H, Perrot-Rochemann C, Bouvier-Durand M, Guern J 1994 Alteration of auxin perception in rolB-transformed tobacco protoplasts. Plant
Physiol. 105: 1209-1215.

Moriuchi H, Okamoto C, Nishihama R, Yamashita I, Machida Y, Tanaka N 2004 Nuclear localization and interaction of RolB with plant 14-3-3 proteins correlates with induction of adventitious roots by the oncogene rolB. Plant J. 38: 260-275.

Murashige T, Skoog F 1962 A revised medium for rapid growth and bioassays with tobacco tissue culture. Physiol. Plant. 15: 471-497.

Nilsson O, Olsson O 1997 Getting to the root: the role of the Agrobacterium rhizogenes rol genes in the formation of hairy roots. Physiol. Plant. 100: 463-473.

Nilsson O, Tuominen H, Sundberg B, Olsson O 1997 The Agrobacterium rhizogenes $\mathrm{rolB}$ and $\mathrm{rolC}$ promoters are expressed in pericycle cells competent to serve as root initials in transgenic hybrid aspen. Physiol. Plant. 100: 456-462.

Radchuk VV, Korkhovoy VI 2005 The rolB gene promotes rooting in vitro and increases fresh root weight in vivo of transformed apple scion cultivar 'Florina'. Plant Cell, Tissue Organ Cult. 81: 203-212.

Röder FT, Schmülling T, Gatz C 1994 Efficiency of the tetracycline-dependent gene expression system: complete suppression and efficient induction of the rolB phenotype in transgenic plants. Mol. Gen. Genet. 243: 32-38.

Somma F, Hopmans JW, Clausnitzer V 1998 Transient three-dimensional modeling of soil water and solute transport with simultaneous root growth, root water and nutrient uptake. Plant Soil 202: 281-293.

Spanò L, Mariotti D, Cardarelli M, Branca C, Costantino P 1988 Morphogenesis and auxin sensitivity of transgenic tobacco with different complements of Ri T-DNA. Plant Physiol. 87: 479-483.

Spena A, Schmülling T, Koncz C, Schell JS 1987 Independent and synergistic activity of $\mathrm{rol} A, B$ and $C$ loci in stimulating abnormal growth in plants. EMBO J. 6: 3891-3899.

Steponkus PL, Lanphear FO 1967 Refinement of the triphenyl tetrazolium chloride method of determining cold injury. Plant Physiol. 42: 1423-1426.

Tanaka H, Toyama J, Hashiguchi M, Kutsuna Y, Tsuruta S, Akashi R, Hoffmannd F 2008 Transgenic superroots of Lotus corniculatus can be regenerated from superrootderived leaves following Agrobacterium-mediated transformation. J. Plant Physiol. 165: 1313-1316.

Tiwari BS, Belenghi B, Levine A 2002 Oxidative stress increased respiration and generation of reactive oxygen species, resulting in ATP depletion, opening of mitochondrial permeability transition, and programmed cell death. Plant Physiol. 128: 1271-1281.

Wang JH, Lin HH, Liu CT, Lin TC, Liu LY, Lee KT 2014 Transcriptomic analysis reveals that reactive oxygen species and genes encoding lipid transfer protein are associated with tobacco hairy root growth and branch development. Mol. Plant-Microbe Interact. 27: 678-687.

Zhu LH, Holefors A, Ahlman A, Xue ZT, Welander M 2001 Transformation of the apple rootstock M.9/29 with the rolB gene and its influence on rooting and growth. Plant Sci. 160: 433-439. 


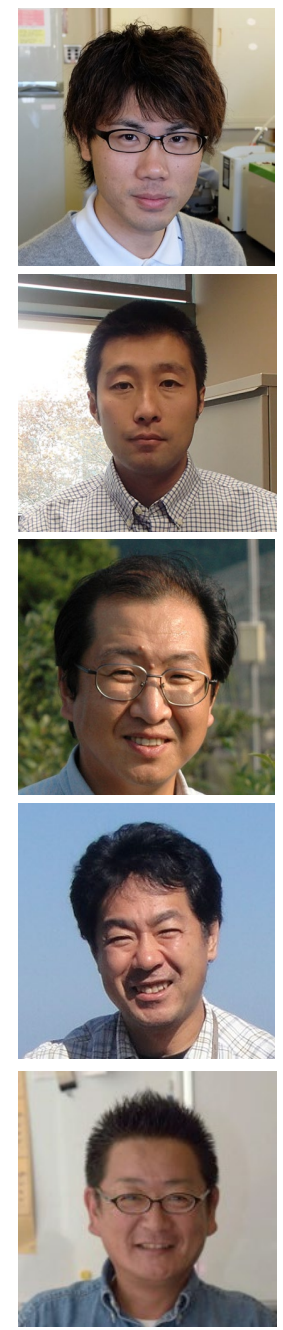

Mr. Tsubasa Yano has studied gene functions related phenotype and physiology in leguminous plant. He is interested in valuable genes enhanced growth and nodulation in leguminous plant.

Dr. Akihiro Yamamoto has studied biochemical and physiological responses of higher plants to environmental stress. He is interested in bioactive nitrogen compounds, such as polyamine, under environmental stress conditions.

Dr. Hisato Kunitake has studied the genetic improvement of fruit crops by biotechnology. His recent research is focused on mechanism of self-incompatibility in Citrus species.

Dr. Yuichi Saeki is a soil microbiologist in the laboratory of soil science and plant nutrition in University of Miyazaki, Japan. His research theme is genomic ecology of soybean-nodulating rhizobia.

Dr. Ryo Akashi is a plant breeder and biotechnology in Faculty of Agriculture, University of Miyazaki, Japan. He has been studying the genetic analysis and root growth in leguminous plants. 